\title{
"A Towering Virtue of Necessity": Interdisciplinarity and the Rise of Computer Music at Vietnam-Era Stanford
}

\author{
by Cyrus C. M. Mody* and Andrew J. Nelson †
}

\begin{abstract}
Stanford, more than most American universities, transformed in the early Cold War into a research powerhouse tied to national security priorities. The budgetary and legitimacy crises that beset the military-industrial-academic research complex in the 1960s thus struck Stanford so deeply that many feared the university itself might not survive. We argue that these crises facilitated the rise of a new kind of interdisciplinarity at Stanford, as evidenced in particular by the founding of the university's computer music center. Focusing on the "multivocal technology" of computer music, we investigate the relationships between Stanford's broader institutional environment and the interactions among musicians, engineers, administrators, activists, and funders in order to explain the emergence of one of the most creative and profitable loci for Stanford's contributions to industry and the arts.
\end{abstract}

\section{INTRODUCTION}

Stanford University's CCRMA, or Center for Computer Research in Music and Acoustics, enjoys a reputation as a world-class computer music and sound research center. CCRMA faculty, staff, and students produce influential musical compositions, develop radical and impactful technologies, cultivate dense ties to other departments and external organizations, and manage an impressive patent portfolio that has yielded tens of millions of dollars in licensing revenue. While today such interdisciplinary cooperation between musicians and engineers may be heralded as a laudable - if still unusual — combination, such an outcome was hardly preordained at the time of CCRMA's early activities in the 1960s and 1970s.

On one level, this article addresses the simple question, Where did CCRMA come from? Our answer to that question, however, unravels a deeper set of issues, couched

\footnotetext{
*History Department, Rice University, MS \#42, PO Box 1892, Houston, TX 77251-1892; Cyrus .Mody@rice.edu.

$\dagger$ Department of Management, Lundquist College of Business, University of Oregon, Eugene, OR 97403; ajnelson@uoregon.edu.

We gratefully acknowledge comments and suggestions from Christina Dunbar-Hester, Patrick McCray, Danny Crichton, and Joseph Klett, as well as from the editors, two anonymous reviewers, and other contributors to this volume. Mody's research is supported by the National Science Foundation via the Center for Nanotechnology in Society at the University of California, Santa Barbara, and the National Nanotechnology Infrastructure Network. Nelson's research is supported by the Ewing Marion Kauffman Foundation. Both authors contributed equally to this article.
}

${ }^{\circledR} 2013$ by The History of Science Society. All rights reserved. 0369-7827/11/2013-0013\$10.00

OSIRIS 2013, $28: 254-277$ 
in Vietnam War-era debates over the role of universities and their relationship to government or military funding. These debates, we argue, formed a milieu out of which interdisciplinary programs such as CCRMA could coalesce, acquire financial and political resources, and, ultimately, become self-sustaining and deeply integrated members of both a university like Stanford and a broad organizational field that combines commercial, academic, artistic, and other activities. We identify specific features of both the institutional environment at Stanford and the particular research conducted at CCRMA that, together, facilitated the center's emergence and growth. We focus specifically on pressures toward interdisciplinarity and "relevant" research, and argue that CCRMA researchers' expertise both in the "multivocal technology" of audio synthesis and processing and in novel forms of interdisciplinary collaboration explains why CCRMA emerged from (and thrived in) this milieu.

Music, science, and engineering were swirling around one another long before the late '60s, as documented by the other chapters in this volume. The core of our argument, however, is that the confluence of many different pressures brought on by the Southeast Asian conflict created an environment at Stanford in which these fields could effectively bind, react, and grow together. Our chapter thus emphasizes the institutional context surrounding the emergence and growth of computer music at Stanford and the ways in which institutional environments and particular developments at the intersection of music, science, and engineering came to be mutually reinforcing.

\section{STANFORD'S TRANSFORMATION IN THE EARLY COLD WAR}

The larger context that helped to facilitate CCRMA was the formation (and then, in the late 1960s, the sudden undermining) of the national science policy regime established in the early Cold War. More than almost any other university, Stanford capitalized on post-World War II changes in federal funding and the emergence of a military-industrial-academic complex to transform from a sleepy, provincial, undergraduate-focused institution into a world-leading research university. Yet that transformation came with a price. When the military-industrial-academic complex experienced crises of funding and legitimacy in the late 1960s, Stanford's dependence on that complex meant that it, in turn, saw steep budgetary declines and student unrest directed at the university's researchers and laboratories. To understand the environment that facilitated CCRMA's emergence, therefore, it is necessary to look back to the early Cold War.

Many hands contributed to Stanford's postwar transformation, but no one more than Frederick Terman. ${ }^{1}$ When he became dean of engineering in 1946, Terman began remolding Stanford to "exploit" the "wonderful opportunity" provided by the Cold War expansion in federal research funding. ${ }^{2}$ Terman largely followed the vision for science policy put forward by his mentor, Vannevar Bush, that came to be known as the "linear model of innovation." 3 This model presupposed that basic scientific re-

\footnotetext{
${ }^{1}$ Material on Terman is drawn largely from Stuart W. Leslie, The Cold War and American Science: The Military-Industrial-Academic Complex at MIT and Stanford (New York, 1993); Rebecca Lowen, Creating the Cold War University: The Transformation of Stanford (Berkeley, Calif., 1997); Eric J. Vettel, Biotech: The Countercultural Origins of an Industry (Philadelphia, 2006).

${ }_{2}^{2}$ Terman, quoted in Lowen, Creating the Cold War University (cit. n. 1), 96.

${ }^{3}$ There is a historiographic debate as to whether Bush should be given credit for the linear model, and even whether there was such a thing. See Benoît Godin, "The Linear Model of Innovation: The Historical Construction of an Analytical Framework," Science, Technology and Human Values 31
} 
search, guided by curiosity and disciplinary conventions and ostensibly uninfluenced by economic gain or societal priorities, would yield generalized, fundamental knowledge that could be applied to specific, technological problems. Bush argued that several war-winning technologies had had their origins in curiosity-driven fields; most notably, the atomic bomb was in part made possible by unguided nuclear physics research that, before the war, had not seemed to have much relevance to military needs. The lesson Bush drew was that the Cold War state needed to invest large sums in basic research. ${ }^{4}$

Similarly, the lesson Terman took from his wartime experiences was "that the training of engineers was inadequate, that they didn't measure up to the needs of the war. ... Most of the major advances in electronics were made by physicists ... rather than by engineers." 5 Thus, back at Stanford, Terman revamped undergraduate engineering education to emphasize fundamental math and physics, and brought in star researchers who could attract federal funding and graduate students for basic engineering science research and who could bring more cutting-edge fundamental physics into engineering.

By prioritizing basic research, Terman also satisfied the Stanford family's directive that the university aid California industry. Faculty who engaged in applied research and development (R\&D) of specific technologies risked competing with off-campus firms. By training students in basic research, however, Stanford's science and engineering departments generated both nonrival knowledge and personnel that flowed easily into the growing local electronics and aerospace sectors.

Terman used both carrot and stick to achieve his vision. In the traditional natural science departments, he used his administrative authority to override and isolate recalcitrant older faculty who were unwilling to take federal money or were too interested in teaching undergraduates, or whose research was not reductionist and fundamental enough. ${ }^{6} \mathrm{He}$ also pushed natural science departments to focus on subfields where fundamental research could easily serve high-tech industry and/or where federal funding was available. Geology, for instance, was steered toward petroleum geology, and physics toward high-energy accelerator research. ${ }^{7}$

In cases where change came too slowly, Terman created new hybrid departments, such as Applied Physics and Genetics, ${ }^{8}$ and reinvented old ones (e.g., Metallurgy

(2006): 639-67; Philip Mirowski, Science-Mart: Privatizing American Science (Cambridge, Mass., 2010); David Edgerton, "The 'Linear Model' Did Not Exist: Reflections on the History and Historiography of Science and Research in Industry in the Twentieth Century," in The Science-Industry Nexus: History, Policy, Implications, ed. Karl Grandin, Nina Wormbs, and Sven Widmalm (Sagamore Beach, Mass., 2004), 31-57; Glen Ross Asner, "The Cold War and American Industrial Research" (PhD diss., Carnegie Mellon Univ., 2006). We are agnostic on this point. We are simply arguing that Bush articulated a justification for investment in basic research that hinged on the possibility that high-tech industries and militarily significant technologies would arise from that research. Over time, economists and policy makers elaborated that justification into what is now known as the linear model-and, over time, Terman elaborated his local implementation of Bush's vision at Stanford to follow suit.

${ }_{4}^{4}$ This is a tendentious interpretation of the importance of basic research in the Manhattan Project and other wartime programs, but one that was widely subscribed to at the time. See Rebecca Press Schwartz, "The Making of the History of the Atomic Bomb: Henry DeWolf Smyth and the Historiography of the Manhattan Project" (PhD diss., Princeton Univ., 2008).

${ }_{5}^{5}$ Terman, quoted in Leslie, Cold War and American Science (cit. n. 1), 54.

${ }^{6}$ Leslie, Cold War and American Science, 167; Vettel, Biotech, 53-65 (Both cit. n. 1).

${ }^{7}$ Lowen, Creating the Cold War University, 80; Leslie, Cold War and American Science, chap. 6 (Both cit. n. 1).

${ }^{8}$ Leslie, Cold War and American Science, 175-81; Vettel, Biotech, 65 (Both cit. n. 1). 
became Materials Science ${ }^{9}$ ) in order to move methods from ostensibly more basic fields into more applied disciplines. He and his allies also created a series of nondepartmental research centers to serve as a bridge between university and industry, and between basic and applied research. First came the Microwave Laboratory in 1944, which early on functioned as the on-campus arm of a local start-up, Varian Associates. ${ }^{10}$ Later centers included the Applied Electronics Laboratory, the Systems Techniques Laboratory, the Solid State Electronics Laboratory, and the Center for Materials Research. Though these centers did much fundamental research, their funding sources (and the most visible short-term applications of their work) were defense related, and the firms to which they had ties were major players in the militaryindustrial complex.

These nondepartmental research centers later provided an important model for CCRMA. For instance, several of these centers had industrial affiliates programs whereby firms could preview faculty research and recruit star students, a feature CCRMA later adopted. However, CCRMA was also molded by the backlash in the late '60s against two prominent characteristics of the early Cold War centers. First, though (as Stuart Leslie notes) these early centers were "interdisciplinary," the interdisciplinarity they embodied was often restrictive: methods and knowledge circulated among the physical and engineering sciences (sometimes with the expressed aim of making engineering more "scientific"), but there was little outreach to economics, law, music, English, political science, medicine, and so forth. ${ }^{11}$ CCRMA, by contrast, was founded in - and exemplified - an era when many stakeholders placed a much higher value on more wide-ranging and egalitarian interdisciplinarity. Second, though these early centers did not avoid civilian funding and applications, their fortunes were largely tied to the national security state. Conversely, while CCRMA did not actively eschew national security funding and ties to the defense industry, it did reflect local and national calls for societal relevance by pursuing highly visible civilian technologies and ties to consumer products firms.

The center to which CCRMA was most closely related was the Stanford Artificial Intelligence Laboratory (SAIL). SAIL's roots can be traced to 1962, when John McCarthy arrived at Stanford and initiated an artificial intelligence (AI) project that built upon a similar project that he and Marvin Minsky organized at MIT in the late 1950s. McCarthy received financial support from the Pentagon's Advanced Research Projects Agency (ARPA) to fund a group of six people, establishing the Stanford Artificial Intelligence Project in 1963. With further support from ARPA, and bolstered by the formation of Stanford's computer science department in 1965, the "project" evolved into a "laboratory" and grew from fifteen people in 1965 to over one hundred by 1968. ARPA continued to provide anywhere from half to two-thirds of the funding in a given year, with NASA, the National Science Foundation (NSF), and the National Institute of Mental Health also providing significant support. ${ }^{12}$

\footnotetext{
${ }^{9}$ Lowen, Creating the Cold War University, 213; Leslie, Cold War and American Science, chap. 8 (Both cit. n. 1).

${ }^{10}$ Leslie, Cold War and American Science (cit. n. 1), chap. 6; Christophe Lécuyer, Making Silicon Valley: Innovation and the Growth of High Tech, 1930-1970 (Cambridge, Mass., 2006), chap. 3.

${ }^{11}$ Leslie, "Playing the Education Game to Win: The Military and Interdisciplinary Research at Stanford," Historical Studies in the Physical Sciences 18 (1987): 55-88.

${ }^{12}$ Lester Earnest, ed., "Final Report: The First Ten Years of Artificial Intelligence Research at Stanford" (Stanford Artificial Intelligence Laboratory Memo AIM-228, July 1973); Bruce G. Buchanan,
} 
A 1973 overview of the first ten years of the project reported that "the work of the Stanford Artificial Intelligence Project has been basic and applied research in artificial intelligence and closely related fields, including computer vision, speech recognition, mathematical theory of computation, and control of an artificial arm."13 In other words, AI provided the underlying raison d'être, but actual applications were envisioned in a wide range of fields. The diversity of projects was matched by a diversity of political perspectives in the AI group, with McCarthy traversing from left to right over the course of the '60s while his deputy director, Les Earnest, moved in the opposite direction. ${ }^{14}$ In both research outlook and political temperament, therefore, SAIL straddled a broad landscape just as the turmoil of the late ' 60 s began. Its capacity to invite participants holding diverse political and disciplinary perspectives would be an important bequest to SAIL's eventual spin-off, CCRMA.

\section{HISTORY OF THE STANFORD MUSIC DEPARTMENT}

The Department of Music followed a rather different trajectory than Stanford's natural, social, and engineering science departments and their associated centers. In fact, Stanford did not have a music department until 1946, more than fifty-five years after the university's founding in 1891. This is not to say that music was not a major part of university life from the earliest days. For example, the Stanford Memorial Church, which occupies a central position on campus both geographically and (at least early on) socially, had an active music program from the start. Yet Stanford's musical activities, such as the band, orchestra, and various glee clubs, were largely initiated by students rather than faculty or the administration. ${ }^{15}$ Formal courses were scarce and a degree program did not exist.

Through the university's first half century, Stanford administrators vacillated as to the place of music. In 1926, for instance, then-president Ray Lyman Wilbur wrote the board of trustees that "funds may be available for a course in harmony and composition as the basis for" the possible formation of "an adequate School of Music along the lines of the Yale School of Music,"16 yet no such action was taken. In fact, it was alumni who moved forward by forming the Friends of Music at Stanford in the mid-1930s. Finally, in 1946, Stanford created a department of music, the last major American university to do so. ${ }^{17}$

The establishment of a department, however, did not ensure its quality and reputation. For example, Stanford remained unranked in the 1957 survey conducted by the

\footnotetext{
"Introduction to the COMTEX Microfiche Edition of Memos from the Stanford University Artificial Intelligence Laboratory," AI Magazine 4 (Winter 1983): 37-42.

${ }^{13}$ Earnest, "Final Report" (cit. n. 12), 2.

${ }^{14}$ John Markoff, "Optimism as Artificial Intelligence Pioneers Reunite," New York Times, 8 Dec. 2009, D4.

${ }_{15}$ Orrin Leslie Elliott, Stanford University: The First Twenty-Five Years (1937; repr., New York, 1977), 198-9.

16 Wilbur to the Honorable Board of Trustees, Leland Stanford Junior University, memorandum, 9 Oct. 1926, Stanford University Archives, Stanford, Calif. (hereafter cited as SUA), SC27, box 17, folder 5, "Board of Trustees Supporting Documents."

${ }^{17}$ M. Tanner, "A Brief History of the Department of Music" (unpublished manuscript, Stanford, Calif., 1978); C. Smith, "Gift Enables Music Department to Construct Long-Needed Facility," Stanford Daily, 14 Jan. 1980, 1.
} 
American Council on Education on quality of graduate faculty in music. ${ }^{18}$ Moreover, Terman's reorientation of the university toward basic research may have run counter to the traditional emphasis on composition and performance-instruction-oriented subjects that were core foci of most academic music departments. Other humanistic departments, most notably Classics, may have offered Music a gruesome example of Terman's attitude toward what he deemed "impractical fields" that could not bring in external research funding or connect to high-tech industry: as provost, Terman stripped Classics of faculty lines, shrank its graduate program, and commanded that its remaining faculty teach only large, lower-level undergraduate courses. ${ }^{19}$ The music department, therefore, was in a remarkably ambiguous and indeterminate position in the mid-1960s, particularly in comparison to its peer departments at other universities. Stanford's department was still emerging on the national scene, still searching out its areas of emphasis, and still uncertain about its place in Terman's university. ${ }^{20}$ That uncertainty and immaturity made the music department ripe for organizational and technological experimentation just as the campus ferment of the Vietnam era began.

\section{VIETNAM-ERA CRISES}

The unrest that gripped Stanford in the late '60s and early '70s was-as on other campuses - a product of many deep divisions in American society. But Stanford was one of a smaller number of universities - such as MIT and Princeton-where the conduct of academic science and engineering was a focus of protest (often in conjunction with other issues, especially the war). ${ }^{21}$ Science-based unrest at Stanford coalesced gradually, beginning in 1966 with debates about classified research on campus. ${ }^{22}$ By the time the administration was forced to terminate its classified contracts in 1969, however, protesting students, reformist faculty, and influential politicians (such as Mike Mansfield and Edward Kennedy) had moved on to a much larger goal: the reconfiguration of the nation's-and hence also Stanford's-research enterprise to prioritize solving civilian social problems above generating fundamental knowledge or contributing to national security.

This coalition articulated - with many variations - a vision of academic science and engineering primarily funded by civilian agencies and emphasizing applied research deemed relevant to social issues such as pollution, energy, mass transit, public housing, and biomedicine. The types of basic research that had been the cornerstone of Terman's Stanford found little favor in the "relevance" agenda. Stanford's Student

\footnotetext{
${ }^{18}$ Kenneth D. Roose and Charles J. Andersen, A Rating of Graduate Programs (Washington, D.C., 1970), 48.

${ }^{19}$ Lowen, Creating the Cold War University (cit. n. 1), 159.

${ }^{20}$ Andrew J. Nelson, "Cacophony or Harmony? Multivocal Logics and Technology Licensing by the Stanford University Department of Music," Industrial and Corporate Change 14 (2005): 93-118.

${ }^{21}$ Vettel, Biotech (cit. n. 1), chaps. 5-6; Stuart W. Leslie, "Time of Troubles for the Special Laboratories," in MIT: Moments of Decision, ed. David Kaiser (Cambridge, Mass., 2011): 123-44; Matthew M. Wisnioski, "Inside 'the System': Engineers, Scientists, and the Boundaries of Social Protest in the Long 1960s," History and Technology 19 (2003): 313-33; Dorothy Nelkin, The University and Military Research: Moral Politics at MIT (Ithaca, N.Y., 1972).

${ }_{22}$ Our discussion of the controversies over classified research at Stanford and the Stanford Research Institute draws on Leslie, Cold War and American Science (cit. n. 1), chap. 9.
} 
Radical Caucus, for example, dismissed basic research as "useless." ${ }^{33}$ More subtle reformists, such as engineering graduate student and activist Stanton Glantz, argued that "the notion of 'basic research' often acts as a smokescreen to hide what we are doing ... [and] to avoid facing the consequences" of academic research for the conflict in Southeast Asia. ${ }^{24}$ Even faculty who had benefited from the early Cold War accumulation of a basic research stockpile, such as Robert Huggins (director of Stanford's ARPA-funded Center for Materials Research) were open to the idea that the time had come to apply that knowledge to "civilian technologies that have lain comparatively dormant in recent years, when primary attention was heavily concentrated upon ... defense- and space-related matters." 25

It is important to note that the deep divisions engendered by calls for relevance were not so much about whether academic research should benefit civil society, but how long it should take for that to happen, how directly that translation should be guided, and whether military funding hindered that translation. Researchers and administrators who were skeptical of the relevance agenda insisted that civilian technologies would result even from work funded by the military. Moderate reformers countered that academic scientists and engineers could and should quicken the pace of translation by seeking nonmilitary funding sources and being more attuned to research areas that would flow more easily into civilian applications. Radicals, meanwhile, believed urgent action was needed. Students for a Democratic Society and other campus activists painted researchers who took defense funding as complicit in the Southeast Asian conflict. In 1969, unrest over Stanford researchers' ties to the military came to a boil, with protesters picketing and chanting outside laboratories, setting fires and stealing classified information, pouring paint on President Kenneth Pitzer, staging a nine-day takeover of the Applied Electronics Laboratory (AEL) and the Systems Techniques Laboratory (STL), and more. ${ }^{26}$

\section{RADICAL INTERDISCIPLINARITY AS A SOLUTION}

The AEL/STL takeover and other confrontations contributed to CCRMA's founding in part by generating a pervasive anxiety about, as Glantz put it, "the possibility of violent confrontation between Stanford's technical and non-technical communities."27 In response, many students, faculty, and administrators articulated the hope that greater cross-disciplinary understanding and collaboration would foster campus cohesion and prevent the breakdown of the institution. As President Richard Lyman put it after the AEL takeover,

If we are in difficulties partly because our functions are many, and our focus can therefore never be single, it will do us no good to try to return to some simpler day. . . . Instead we ought to glory in the fact that some people are learning to appreciate Keats in one part of

${ }^{23}$ Student Radical Caucus, "Fire and Sandstone: The Last Radical Guide to Stanford," n.d. [almost certainly 1969], William Rambo Papers SC 132, ACCN 97-093, SUA, box 6, folder 10, "Student Unrest, 1968-2."

${ }^{24}$ Glantz, "Comments about Engineers for Engineering by an Engineer," Grindstone: A Forum for Controversial Issues of Special Interest to the Engineering Community-Sponsored by the StudentFaculty Liaison Committee of the School of Engineering, 30 Nov. 1970, 4-16, SUA, Arch 3009 The Grindstone.

${ }^{25}$ Quoted in Leslie, Cold War and American Science (cit. n. 1), 232.

26 Ibid., chap. 9.

${ }^{27}$ Glantz, "Comments about Engineers" (cit. n. 24). 
the campus, while others are solving problems of linear programming in another. Glory in it, and make a towering virtue of necessity by exposing the one group to the other, and each to a thousand further groups, at every available opportunity. ${ }^{28}$

The interdisciplinarity thought necessary to preserve Stanford and to quiet unrest was far more wide-ranging and egalitarian than that promoted earlier by Terman. Terman's interdisciplinarity had been a matter of regrounding engineering and social science disciplines in the ostensibly more fundamental knowledge of the natural sciences. Campus activists and faculty reformers of the Vietnam era, however, argued that the pressing social problems of the day were so complex as to require equal partnerships, not hierarchical relationships, ranging all across the social and natural sciences, engineering, and the humanities. As Stephen Kline, an engineer who cofounded Stanford's Values, Technology, and Society (VTS) program, put it, "The kinds of questions that do and should concern the students are: Do you build the SST [supersonic transport], and what is being done about smog? Questions of this sort cannot be seen clearly through the viewpoint of any single discipline." ${ }^{29}$ Instead, Kline's VTS program offered a new approach, with "various combinations of scientists, engineers, philosophers, historians, anthropologists, psychologists, psychiatrists, sociologists, ethicists, and theologians-all working very closely together." 30

Even skeptical faculty members and administrators in the Vietnam era commonly conflated "interdisciplinary" with "applied" or "relevant" research and/or painted discipline-based research as the opposite of "problem-oriented" research. As President Lyman put it in 1971, "No matter how earnestly the effort is made by scholars to mount collaborative attacks on social problems, ... results are bound to be slow and halting. . . . It will take more than some marriages among academic disciplines." 31 Nevertheless, Lyman saw where things were headed: "If we succeed, as I trust we shall, in increasing the amount of multi-disciplinary, problem-oriented research that we do, this will happen in part because money is beginning to become available for such work from the Congress and from federal agencies." 32

Thus, even skeptics of reform could be persuaded to embrace a more radical form of interdisciplinarity in the late ' 60 s and early ' 70 s because the rapidly changing federal funding situation offered strong incentives to do so. In part, there was simply less money to go around: federal nondefense R\&D budgets declined by close to 30 percent from 1966 to $1976 ;{ }^{33}$ total federal R\&D funding reached a peak of 3 percent of GDP in 1964 and declined steadily until the 1980s. ${ }^{34}$ At the same time, civilian funders such as the NSF, the National Institutes of Health, and the Environmental Protection Agency began siphoning federal research funds away from national

\footnotetext{
${ }^{28}$ Quoted in "Defense Research Will Shift if Forced out of Universities," Campus Report, 23 Sept. 1970 .

29 "Values, Technology, and Society Included in Experimental Program," Campus Report, 19 May 1971.

${ }^{30}$ Ibid. Stanford later renamed the VTS program VTSS (Values, Technology, Science, and Society) and then STS (Science, Technology, and Society).

31 "Revolt against Reason Can Have 'Ominous Consequences,"” Campus Report, 1 Jan. 1971.

32 "Lyman Looks at Future: Toward a More Open University," Campus Report, 14 Apr. 1971.

${ }^{33}$ Intersociety Working Group, American Association for the Advancement of Science, AAAS Report XXXIII: Research and Development, FY 2009 (Washington, D.C., 2009), 24.

${ }^{34}$ Homer A. Neal, Tobin L. Smith, and Jennifer B. McCormick, Beyond Sputnik: U.S. Science Policy in the 21st Century (Ann Arbor, Mich., 2008), 81.
} 
security agencies, and shifted their emphasis toward applied research and engineering at the expense of basic science.

Given the unstable funding situation, Stanford researchers and administrators could see that the best strategy would be for individual faculty members to diversify their funding sources and reorient to Congress's new priorities. More radical interdisciplinarity was one way to appeal to a wider set of funders, while simultaneously dampening campus unrest. Thus, Stanford saw a dramatic mushrooming of interdisciplinary degree-granting centers in this era: a doubling in the number of such centers between 1968 and 1969, and a seven-times-higher rate of incorporation of such centers over the next twenty years than over the previous twenty. Most of these new centers were anchored in the humanities or social sciences, perhaps because, as Jamie Cohen-Cole has shown, an ideology of interdisciplinarity took hold of American social science in the ' 50 s. ${ }^{35}$ Indeed, when the university founded a Center for Interdisciplinary Research in 1972, it used an existing interdisciplinary social science center, the Institute for Public Policy Analysis, to nucleate a broadening of "the scope of interdisciplinary research activities to include engineering, the physical sciences, the professional schools and humanities, as well as economics and the social sciences." 36

In the School of Engineering, meanwhile, many of the faculty housed in the extradepartmental research centers of the Terman era were, by the late ' 60 s, searching for civilian applied projects, diversified funding sources, and (consequently) a broader type of interdisciplinarity. Stanford's electrical engineers - an important constituency for CCRMA's later explorations into computer music-were particularly prominent in turning toward interdisciplinary and applied, civilian projects such as biomedical technologies and aids for the handicapped. As John Linvill, chair of Electrical Engineering (EE), put it in a 1967 memo, "Stanford University can and should become more effective in studying and attacking the problems of today's society. Electrical Engineering, with its aim to bring technological tools to the solution of man's problems, is interested to join with other departments in working on these contemporary problems ... [ [such as] environmental studies, urban problems, problems of developing countries, etc.... [which] cannot be attacked within a single discipline." 37 Few Stanford engineers altogether abandoned defense-funded projects, whether out of budgetary necessity or because they saw such work as both good science and good citizenship. Yet whatever their politics, many Stanford engineers were clearly moving in the late ' 60 s toward work of the kind called for by antiwar reformers.

The situation in the late '60s and early ' 70 s, then, was that the different parts of campus that would eventually contribute to CCRMA faced convergent pressures. For members of the still-unsettled music department, incentives for moving toward the Terman model by cooperating with engineers to bring in external basic-research

${ }^{35}$ Cohen-Cole, "Thinking about Thinking in Cold War America" (PhD diss., Princeton Univ., 2003).

${ }^{36}$ Nancy Donham, Stanford University News Service release on the Center for Interdisciplinary Research, 10 July 1972, SUA, Stanford University Sponsored Projects Office SC 344, box 14, folder "Center for Interdisciplinary Research (CIR), 1972-1974."

37 John G. Linvill, executive head, Department of EE, to the Committee for the Study of Stanford's Educational Program, memorandum, "Re: Comments of Electrical Engineering on Stanford's Educational Programs and Objectives," 26 Jan. 1967, SUA, Calvin Quate Papers SC 347 (83-033)—1987 accession, box 3, binder "Electrical Engineering." 
funding and to grow links with industry would have been apparent. Stanford's predominantly defense-funded engineers and computer scientists, meanwhile, could perceive incentives to modify the Terman model by cooperating with musicians and other humanists to demonstrate civilian applications. In such an environment, an emerging center that was interdisciplinary by nature, that addressed practical applications, that developed and leveraged technologies applicable in multiple settings, and that could garner external resources for these activities would suddenly find itself the embodiment of new organizational perspectives and priorities.

\section{CCRMA'S ROOTS: “FOOLING AROUND” AND CHANCE ENCOUNTERS}

John Chowning, CCRMA's cofounder and its most conspicuous initiator, arrived at Stanford in 1962 in order to pursue a doctoral degree in music composition. He had earlier studied composition in Paris, where he was exposed to-and intrigued byelectronic music. Upon his arrival at Stanford, with its newly created music department, however, he was dismayed to find that there were neither facilities for electronic music nor an interest in creating them.

Nevertheless, Chowning's interest in the field was known to others, including his fellow members of the Stanford Symphony Orchestra. In January 1964, one of these members passed him a copy of an article from Science that described how a computer could be used as a musical instrument. (The orchestra member's husband subscribed to Science because he was on the faculty at Stanford Medical School.) The article's author was Max Mathews, a researcher at Bell Telephone Laboratories. There, computer music developed from an attempt to create tones that would resemble speech but be more amenable to analysis. As Mathews and his colleague, John Pierce, put it,

There is a very close analogy between the voice and a bowed-stringed instrument. ... Concepts and analytical techniques developed in speech research should be useful in studying the sounds of bowed-stringed instruments, and in fact much of the computerprogramming and all of the peripheral equipment used in this study were originally designed for speech research. ${ }^{38}$

Mathews's repositioning of the computer as a musical instrument thus reflects the discussion by John Tresch and Emily Dolan (in this volume) of "telos," or the ends to which instruments are used. Mathews's insight was to use music to simplify his data while at the same time importing a tool used for other purposes - the computerinto the world of music.

Critically for CCRMA, Mathews and Pierce were open to collaboration and conversation with musicians. In fact, Mathews, Pierce, and other Bell engineers collaborated with several artists in 1966 to produce a series of performance-art presentations, 9 Evenings: Theatre and Engineering. ${ }^{39}$ Mathews and Pierce were also closely

\footnotetext{
${ }^{38}$ Mathews, Joan E. Miller, Pierce, and James Tenney, "Computer Study of Violin Tones-Case 25952," Bell Labs technical memorandum, 15 Nov. 1965, John Pierce Papers, Huntington Library, San Marino, Calif. (hereafter cited as Pierce Papers), box 7, binder "Technical Memoranda 19561968."

${ }^{39}$ P. Miller, "The Engineer as Catalyst: Billy Kluver on Working with Artists," IEEE Spectrum 35 (July 1998): 20-9. More generally, Mathews, Pierce, and Chowning were leading exemplars of the heightened mutual regard and interaction among engineers and artists in the 1960s, particularly in
} 
connected to Stanford through faculty members in applied physics and EE who had formerly worked at Bell Labs. Thus, Chowning was able to visit Mathews the summer after taking a computer programming course in the spring of 1964. Mathews provided Chowning with direction and, crucially, the Music IV computer program that Mathews had created to generate computer sound on Bell's IBM 7090.40

Computers were somewhat rare commodities at the time, however, and Chowning's search for one on which to implement Music IV led him to the rapidly expanding Stanford Artificial Intelligence Project. As he recalled:

In autumn of ' $64 \ldots$ I met Dave Poole. I had this box of [punch] cards from Max [Mathews]. We knew one another from the Stanford orchestra. He was a tuba player and I was a percussionist, so we were right next to one another. . . Poole was an applied math major, maybe in his second or third year. He was a hacker. He was sort of on the periphery of the AI lab. ${ }^{41}$

With support from Poole, whose programming skills had become indispensable to the AI project, and from Les Earnest, the AI project's deputy director and the husband of a local music teacher, Chowning implemented Mathews's program on the AI project's PDP-1 computer later that year. Over the next several years, Chowning continued his work on computer-synthesized and manipulated sound, receiving his doctoral degree in 1966 and joining the music department faculty that same year. He had a major breakthrough in 1967, when some late-night "fooling around" (as Chowning himself describes $\mathrm{it}^{42}$ ) resulted in the discovery of frequency modulation synthesis, a technique that permits the creation of complex sounds with relatively few computations. Yamaha Corporation of Japan ultimately licensed the technique in 1975, and, after several more years of development by Yamaha and Stanford, it formed the basis of a suite of electronic musical instruments that was extremely profitable for both organizations. Once CCRMA was founded, its personnel built an active industrial affiliates program and an intellectual property portfolio of several dozen patents. Today, they contribute to a wide range of companies, many of which they started. The center itself is now one of the world's premier places for computer music and digital audio research. ${ }^{43}$

CCRMA's success had many sources. In part, it benefited from ties to firms such as AT\&T and Yamaha and to the emergence of a global computer and electronic music community. CCRMA was also fostered in part by features of Stanford's music de-

New York (near which Bell Labs was located) and the Bay Area (including Stanford). See Matthew Wisnioski, Engineers for Change: Competing Visions of Technology in 1960s America (Cambridge, Mass., 2012); Andrew Pickering, The Cybernetic Brain: Sketches of Another Future (Chicago, 2011); Christina Dunbar-Hester, "Listening to Cybernetics: Music, Machines, and Nervous Systems, 19501980," Sci. Tech. Hum. Val. 35 (2010): 113-39.

40 M. V. Mathews, "The Digital Computer as a Musical Instrument," Science 142 (1 Nov. 1963), 553-7. Chowning recalled the sequence of events in a 25 Mar. 2008 interview with Andrew Nelson in Palo Alto, Calif. Pieces of the story are captured in other accounts, too, including an interview of Chowning conducted by Vincent Plush on 31 May 1983 in Palo Alto as part of the Yale Oral History Project.

${ }^{41}$ Chowning, interview by Nelson (cit. n. 40).

${ }^{42}$ Chowning, interview by Plush (cit. n. 40 ).

${ }^{43}$ For other accounts of CCRMA's growth and the Yamaha relationship, see Nelson, "Cacophony or Harmony" (cit. n. 20); Tim Reiffenstein, "Codification, Patents and the Geography of Knowledge Transfer in the Electronic Musical Instrument Industry," Canadian Geographer 50 (2006): 298-318; Bob Johnstone, We Were Burning (New York, 1999). 
partment. For example, the department's relative youth meant it had not developed a coherent internal identity around any one particular program. Rather, the music department at the time was experimenting with programs such as jazz studies, performance practice, and early dance, all of which were products of individual faculty members' initiative. Support from music department faculty members proved critical to Chowning's graduate studies, too. Under the chair system that was in place, graduate students could pursue any topic that their adviser supported, regardless of departmental interests or pressures. As Chowning recalled in 1982, "Not many universities would have allowed me the freedom to do what I've done." ${ }^{44}$ The music department's policies thus enabled Chowning's unusual exploration of computer music.

CCRMA also benefited from a variety of fortuitous encounters and events, both inside and outside Stanford. These included Chowning's fellow orchestra member passing him Mathews's Science article, Mathews's willingness to share his computer program, Poole and Chowning's collocation in the Stanford symphony and Poole's subsequent assistance in implementing the computer code, and Chowning's latenight fooling around. Absent any of these, CCRMA's history might have unfolded quite differently. Yet these coincidences, as well as the felicitous characteristics and policies of the music department, had such an impact on CCRMA's development because of the larger institutional environment. That environment, as we have argued, was shaped by Vietnam-era tensions and budgetary conditions that incentivized practical applications and wide-ranging interdisciplinary collaboration.

\section{INTERDISCIPLINARITY AND CCRMA'S TIE TO PRACTICAL APPLICATIONS}

On one level, the very term "computer music" implies an interdisciplinary connection. Nevertheless, it is instructive to unpack the ways in which the activities at CCRMA reflected the more radical interdisciplinarity that emerged in the 1960s. This disciplinary diversity was evident, in part, in individuals such as Chowning himself. In writing of Chowning's promotion to full professor, for instance, the spring 1979 music department newsletter noted,

Chowning's achievements in composition, teaching and research touch upon several disciplines. His research has been primarily in acoustics and psychoacoustics (the psychology of sound perception). He has developed computer techniques for creating the illusion of sound localization and movement through space, for artificial reverberation, and for synthesizing and generating any sound that can be produced by loudspeakers. ${ }^{45}$

Chowning and his associates were quick, however, to point out that no individual alone could master the wide variety of disciplines that contribute to computer music.

For instance, F. Richard Moore, a former CCRMA student who went on to build the computer music program at the University of California, San Diego, described the epistemic challenge of computer music this way in 1979:

The complexity of the new technological tools ... require[s] cooperative team efforts for their use. Musicians have traditionally worked in highly individualistic ways ...

${ }^{44}$ Stanford Department of Music, "Computer Music Comes of Age," Music at Stanford, Oct. 1982. Included with the Stanford Observer, Oct. 1982, sec. 2.

${ }^{45}$ Stanford Department of Music, "Chowning Appointed to Full Professorship," Music at Stanford, Spring 1979, 1. 
[but] using computers to study music requires simultaneous attendance to . . . computer science, engineering, acoustics, psychoacoustics, and music. . . . It is unlikely (or at least rare) that individuals will possess all of the requisite skills and knowledge needed for effective use of computers in music making or study. ${ }^{46}$

Moore's reflections are not entirely new, of course: science and music share deep historical connections, as documented throughout this volume. The interdisciplinarity imagined and implemented by Chowning and Moore, however, involved multiple participants contributing unique - and equally valued - expertise, rather than individual scientist-musicians or scientists such as Helmholtz or Mach (on whom see, respectively, Kursell and Hui in this volume), who combined different forms of expertise in a single person.

Thus, CCRMA addressed the challenge of interdisciplinarity by bringing together individuals who were highly skilled in their particular disciplines but also reliant upon other individuals to fully realize their objectives. Rather than smothering individual creativity (which Moore cautioned that musicians would resist), CCRMA leveraged interdisciplinary teamwork to enable the full expression of individualistic goals. Contemporary descriptions of the center, in publications ranging from the Stanford campus newspaper to Newsweek to Rolling Stone, emphasized these interdisciplinary underpinnings. In fact, of the dozens of articles published on CCRMA in the 1970s, every one mentions the word "interdisciplinary," with most pieces dwelling at length on the range of disciplines found at the center.

The form of that interdisciplinarity was precisely fitted to the convergent incentives faced by different parts of the Stanford campus. As Chowning and two colleagues wrote in a 1974 grant proposal made jointly to the NSF and the National Endowment for the Arts (NEA),

A major contribution to present and future music exists in the application of a rapidly developing computer technology to the art and science of music. The extraordinary results already obtained have occurred in those few instances where scientists and musicians have taken the opportunity to bring their respective skills to bear on problems of common interest in a rich interdisciplinary environment. It is an example of cooperation, but more, an expression of the freedom of intellect and invention, where creative minds from diverse disciplines have joined in a common goal to produce fundamental knowledge which must be the source for new music, and to produce works of art which reflect the scientific-technological riches of the present. ${ }^{47}$

That is, NSF funding for CCRMA would enable the center to expose musicians to the methods and values of scientists and engineers, allowing researchers to "produce fundamental knowledge" for the "science of music"-exactly the model established by Terman. At the same time, CCRMA would assist scientists and engineers in the "application of a rapidly developing computer technology to the art" of music "in a rich interdisciplinary environment"-exactly the kind of humanistic collaboration

\footnotetext{
${ }^{46}$ Moore, "The Nature of Music Research," Directions: Center for Music Experiment and Related Research (newsletter, University of California, San Diego), Dec. 1979, 1-2.

${ }^{47}$ John M. Chowning, Leland C. Smith, and Albert Cohen, "The Computer Music Facility: A New Musical Medium," proposal submitted to the NEA in conjunction with the proposal "Computer Simulation of Music Instrument Tones in Reverberant Spaces" submitted to the NSF, 18 June 1974, SUA, CCRMA ACCN 2001-262, box 7.
} 
and civilian application that would bring diversified funding and approval from campus activists.

The structure and location of CCRMA within the broader university environment played a critical role in facilitating this disciplinary mixing. Current CCRMA director Chris Chafe, who arrived as a graduate student in the late 1970s, has argued that, on the one hand, CCRMA's administrative home in the music department is critical for attracting music personnel to the collaboration: "This is a cross-disciplinary, very artistic, technical, everybody-helping-each-other kind of environment. . . . Imagine the facility being located in a more technical department, what the barrier would be for musicians approaching. Would they feel they're free to come join the project if it were headed towards engineering?" 48 On the other hand, as Chowning recalled in 1982, CCRMA's early leaders "felt the separation [from the music department] was necessary because our work was different from the usual Music Department activity." 49

In fact, CCRMA has always been physically separated from the rest of the music department, following the model of earlier semi-independent research centers: for example, the Center for Materials Research was aligned with, but not part of (or limited in its personnel to) the materials science and engineering department; the Integrated Circuits Lab was aligned with, but not part of or limited to the EE department. Chowning and other CCRMA leaders recognized that the trick was to be both separate from and connected to a variety of groups simultaneously. As Chowning remarked in 1975, "Every center tends to build a wall around itself. . . . We hope to provide intellectual ventilation as well as coordination." ${ }^{50}$ CCRMA, therefore, thrived at an almost contradictory intersection between autonomy and authority, connectedness and isolation, individualism and teamwork. In a university environment struggling to find the appropriate organization for interdisciplinary activities, such ambiguity advantaged a group that could not quite be categorized and might, therefore, be all things to all people (or, at least, many things to many people).

At the center of CCRMA's multivalent milieu were the computer and associated sound-generating and processing algorithms. We label these tools "multivocal technologies" in reference to their ability to span both disciplinary boundaries and areas of applied interest. A multivocal technology exhibits generality and flexibility, and is subject to different interpretations depending on the group that employs or interacts with it. Our conceptualization of multivocal technologies differs from "boundary objects," though it certainly shares features in common with this concept. Fundamentally, boundary objects facilitate communication between diverse groups, enabling them to arrive at a shared understanding and to work together. ${ }^{51}$ As is highlighted by the interdisciplinary context of CCRMA, a multivocal technology such as the computer can, like a boundary object, permit groups to work together; however, it does so in a way that is more reflective of Peter Galison's "trading zones"-where different

${ }^{48}$ Chafe, interview by Andrew Nelson, 7 Mar. 2002, Stanford, Calif.

49 J. Bailie, “Computer Music: A Trend That's Caught Fire," Stanford Daily, 20 July 1982, 7.

${ }^{50}$ Paul Hertelendy, "Stanford's Musical 'Marriage,"” Oakland Tribune, 12 Jan. 1975, 20.

${ }^{51}$ Susan Leigh Star and James R. Griesemer, "Institutional Ecology, 'Translations' and Boundary Objects: Amateurs and Professionals in Berkeley's Museum of Vertebrate Zoology, 1907-39," Social Studies of Science 19 (1989): 387-420; Paul R. Carlile, "A Pragmatic View of Knowledge and Boundaries: Boundary Objects in New Product Development," Organization Science 13 (2002): 442-55; Beth A. Bechky, "Object Lessons: Workplace Artifacts as Representations of Occupational Jurisdiction," American Journal of Sociology 109 (2003): 720-52. 
parties do not need to agree about the context of collaboration-than it is of boundary objects. ${ }^{52}$

More pointedly, our inspiration for multivocal technologies draws, in part, on John Padgett and Christopher Ansell's work on the Medici family in Renaissance Italy, which derived power from its ability to maintain separation between networks of political, economic, and social influence; the relationship illustrated by Padgett and Ansell is not so much focused on bringing together through commonality as it is on lying between by presenting different faces to different groups. ${ }^{53}$ Thus, multivocal technologies not only embody a high level of interpretive flexibility, but also enable participants to exploit this interpretive flexibility to serve different ends depending on the pattern of relationships in play. ${ }^{54}$

That is, multivocality is intentional, even Machiavellian. Actors must choose to position themselves where they can sing different tunes to different audiences so that they can obtain resources from each audience. Other historians of technology have observed that computers and musical instruments have been useful "liminal entities" with which actors can mediate between different groups. ${ }^{55}$ Particularly in the late 1960s, electronic musical instruments allowed such individuals to perform a "legitimacy exchange," whereby technologists accrued social capital from artists and vice versa. ${ }^{56}$ Our study goes somewhat further, however, in showing how the multivocality of a technology (the computer) was amplified by innovation in the form of an organization (CCRMA).

The computer is not an inevitably multivocal technology, but it has been made multivocal in many different institutional contexts, including CCRMA. As Dick Moore wrote in 1979, "The computer may be viewed as a general purpose tool with the unprecedented function of extending our power of mind, as other tools extend our muscular or sensorial powers." ${ }^{77}$ Chowning and others repeatedly emphasized the broad appeal of the computer as a research tool in gathering resources and accruing prestige for CCRMA. For example, the 1974 application to the NEA referenced above cited the research applications of the computer at Bell Labs, claiming, "Based on this past experience, the proposed [CCRMA] facility will maintain those attributes of generality, flexibility, and precision which have been of utmost importance in the research performed to date." 58

As we have seen, Bell Labs researchers such as Mathews and Pierce employed the computer (almost literally) as a multivocal technology, not simply for generating and analyzing musical sounds, but also for building a diverse network of interlocutors interested in computer music: for example, Yale composer James Tenney, President Nixon's science adviser Edward David, and science fiction author Arthur C. Clarke. Pierce and Mathews in turn openly admired Chowning and CCRMA's similar use of

\footnotetext{
${ }^{52}$ Galison, Image and Logic: A Material Culture of Microphysics (Chicago, 1997).

${ }^{53}$ Padgett and Ansell, "Robust Action and the Rise of the Medici, 1400-1434," Amer. J. Sociol. 98 (1993): 1259-319.

${ }^{54}$ Wiebe Bijker, Thomas Hughes, and Trevor Pinch, eds., The Social Construction of Technological Systems: New Directions in the Sociology and History of Technology (Cambridge, Mass., 1987).

55 Trevor Pinch and Frank Trocco, Analog Days: The Invention and Impact of the Moog Synthesizer (Cambridge, Mass., 2004).

${ }^{56}$ Fred Turner, From Counterculture to Cyberculture: Stewart Brand, the Whole Earth Network, and the Rise of Digital Utopianism (Chicago, 2006).

57 Moore, "Nature of Music Research" (cit. n. 46), 2.

58 Ibid., 3.
} 
the computer as both a musical technology and the centerpiece of a heterogeneous network. As Pierce put it in letters of recommendation for Chowning,

Most musicians shy away from the computer and need a great deal of help to use it effectively. Chowning not only knew how to make the computer work; he knew what to do with it. ... In a day when many artists mouth science vainly, it is rare but extremely pleasing to find one, John Chowning, who understands and uses science. ${ }^{59}$

Or, more succinctly, "Chowning has contrived to show great originality and leadership. Starting from essentially nothing, he has brought diverse talents together into a field of common general interest." 60

Endorsements from Bell Labs carried special weight at Stanford given Mathews's and Pierce's strong ties there. Mathews took a sabbatical in the Stanford Artificial Intelligence Project in 1969, and both he and Pierce eventually took faculty positions affiliated with CCRMA. Both men were also in regular contact with former Bell Labs team members at Stanford, including John Linvill (chair of EE) and Calvin Quate (in EE and applied physics, but also-on temporary assignment—an associate dean with oversight of Chowning's tenure case). Indeed, Quate sought Pierce's help in 1970 in securing philanthropic funding for his own answer to the relevance agenda, an acoustic microscope for biological research - in response to which Pierce teasingly asked whether the microscope was "fire resistant and bomb proof? Or, are things now quiet at Stanford?"61

Thus, CCRMA researchers' emphasis on generality allowed them to connect to broader networks that employed the same central tool and to draw legitimacy from their connection to those networks. Indeed, CCRMA researchers pushed the generality of their approach to extremes in search of funding and interlocutors. For example, a 1977 NSF grant application argued, "The work to be performed under this project is directed toward answering basic questions about the variety of forms in which information can flow between man and computer, and the factors which limit the rate of this information flow." 62 Here, music was the concrete context, but the use of a multivocal technology in that context enabled musicians to contribute to a highly abstract debate about the nature of information of the kind traditionally associated with physics, math, and EE.

The multivocality of the computer was indispensable in helping CCRMA's leaders satisfy the sometimes conflicting demands on faculty members at research universities in the 1970s. On the one hand, the computer aided CCRMA personnel in doing the kind of basic research that would establish their scientific credibility. As one reviewer of a 1977 NSF grant wrote, "In past proposals the National Science Foundation has had to consider whether it was supporting music as an art or whether it was supporting a scientific study. In this proposal, there is no question about the

\footnotetext{
${ }^{59}$ Pierce to Albert Cohen, Department of Music, Stanford, 21 Mar. 1978, Pierce Papers, box 5, folder "Misc. Correspondence H-Z, 1973-79."

${ }^{60}$ Pierce to Wolfgang Kuhn, Department of Music, Stanford, n.d., Pierce Papers, box 5, folder "Misc. Correspondence, H-Z, 1973-79."

${ }^{61}$ Pierce to Quate, 19 Oct. 1970, Pierce Papers, box 5, binder "Correspondence, External, August 1969-March 1971."

62 John Chowning and Loren Rush, "An Interactive Graphical Environment for Musical, Acoustical, and Psychoacoustical Research," project summary for NSF grant no. MCS77-23743, 1977, SUA, CCRMA ACCN 2001-262, box 7.
} 
focus of the effort. The work is entirely of a scientific nature; only the applications concern music." ${ }^{33}$ Chowning himself reinforced this rhetoric. For example, in a 1982 student-newspaper story reporting that "since 1975, CCRMA has received over \$1 million from the NSF to support its work," Chowning explained, "These grants have been based on the scientific aspects of our work in psycho-acoustics and signal processing." 64 That is, for some audiences, music provided the context of CCRMA's work, but the focus was on scientific advance.

On the other hand, some CCRMA personnel and external commentators recognized that music was not only a convenient context, but also a top beneficiary of research support. For example, another reviewer of the 1977 NSF grant emphasized that the musical implications of CCRMA's proposed research were exciting precisely because of their impact on a field of "practical" and "applied" importance (music):

The timbre perception proposal is superb! It is a pattern for the kind of research that should be emphasized today. It is one of the too rare cases where scientific studies are making real contributions to an area of great applied importance. There are plenty of areas where good scientific methods are discovering interesting new things about the world, but often the new information does not have clear importance in applications. Likewise, there are plenty of important practical problems, but too often scientific methods can make only weak contributions to their solutions. The fundamental studies proposed here can produce information of enormous importance to music, both for immediate applications and for the far future. ${ }^{65}$

Six years later, a reviewer of another NSF grant also identified the arts not as a convenient context for fundamental research, but as a full participant in, and beneficiary of, CCRMA's brand of interdisciplinary, applied research:

I cannot recommend this proposal more highly.... How many projects combine and bear fruit in fields as diverse as signal processing, artificial intelligence, and acoustics, while having profound implications in the arts? The benefits of such research to the music recording industry are clear. ${ }^{66}$

Thus, in the hands of CCRMA personnel, the computer allowed for continual feedback and alternation in the relationship between musical instrument and research. Not only was the musical instrument useful as a research tool-as in the accounts provided by Pesic and Kursell in this volume, as well as others-but insights about the research tool were made useful in a musical context as well.

Indeed, the blurring of distinctions among scientific research, technological development, and musical composition is reinforced by a peculiar feature of computer music. In traditional composition, the instruments are (relatively) fixed and the composition process focuses upon orchestration and the specific notes to be played by each instrument. In computer music, however, the instruments themselves need to be "composed" via computer code. The sonic possibilities are, therefore, unknown

\footnotetext{
${ }^{63}$ Reviewer comments on NSF proposal no. BNS-7722305, "Experiments in Timbre Perception," submitted by John Chowning and John Grey, 1 Sept. 1977, SUA, CCRMA ACCN 2001-262, box 7.

${ }^{64}$ Bailie, "Computer Music" (cit. n. 49).

${ }^{65}$ Reviewer comments on "Experiments in Timbre Perception" (cit. n. 63)

${ }^{66}$ Reviewer evaluation form for NSF proposal no. MCS-8214350, "An Intelligent System for the Knowledge-Driven Analysis of Acoustic Signals," submitted by John Chowning, 18 Feb. 1983, SUA, CCRMA ACCN 2001-262, box 7
} 
prior to-and become known through-composition. At CCRMA (as described by composer Michael McNabb, who earned his PhD there in the 1970s), the process of composing "instruments" and composing "music" was often iterative and involved the distributed cognition of an interdisciplinary team:

It's really hard to even separate where all the creativity came from. When you talk about one piece of music, any one piece of music, there couldn't help but be at least half a dozen people involved besides the composer because we had to write our own software, the engineers had to build their own equipment, all this stuff. It was like you'd lose track: Did Julius [Smith, an electrical engineer] come up with this special [engineering] thing and we thought, "Well, that's cool. I'm going to use it in a piece." Or the other way around: "I want to do X" and they [people like Julius Smith] would say, "Well one way you could do that is like this." 67

Compositional and research activities, and musical and technical activities, were inseparable. For this reason, many observers felt that CCRMA represented a new marriage between art and science. Each field benefited independently; science and engineering benefited art and, crucially, art provided a path forward for new scientific and technological developments.

By helping to blur these different domains, the computer facilitated CCRMA's reach beyond the ivory tower of research to engage the world of musical performance and appreciation directly. For example, in 1975, the Stanford Daily interviewed CCRMA personnel who downplayed "academic" activities and instead emphasized the practical applications of computer music:

Fears that computer music will be "highly academic" are "clearly silly," Moorer stated. . . . "Computer music may be a 'laboratory thing' now but in five to 10 years," Moorer predicted, it will be a suitcase-size "performing stage popular instrument." The computer as a musical instrument could eventually "find its way into everyone's home," Grey added. ${ }^{68}$

Chowning, too, asserted (in 1979), "This is not an acoustical lab. We define our problems as 'real-world' problems; we don't use anechoic chambers [sound-absorbing rooms common in acoustics research environments] because nobody listens in one." 69

This connection to "real-world" problems of performance allowed CCRMA to appeal for funding not just from civilian research-funding agencies such as the NSF, but also from arts organizations such as the NEA and the California Arts Council, and from commercial firms and industry groups. CCRMA's research tools were also multivocal enough to appeal to defense funding agencies, especially as time went on and defense R\&D budgets bounced back (while the stigma associated with such funding waned). Indeed, by 1985, Stanford's Sponsored Projects Office was advising CCRMA to mine the intersection of civilian and national security funding: "NSF is mixed in with Navy and DARPA. ... Helpful buzzwords on their interests include:

\footnotetext{
${ }^{67} \mathrm{McNabb}$, interview by Andrew Nelson, 17 Apr. 2009, San Francisco.

${ }^{68}$ Ann Amioka, "Computers Add New Dimension to Music," Stanford Daily, 5 Mar. 1975. Andy Moorer was an EE PhD student who would go on to develop the sound studio for LucasFilm and to found the firm Sonic Solutions. John Grey was a psychology doctoral candidate. It's worth noting that Grey's prediction was prescient: through LucasFilm, Moorer did bring computer music into every home, and the CCRMA-enabled Yamaha FM synthesis chip powered the first wave of sound cards in multimedia home computers.

${ }^{69}$ Michael Walsh, “Applying New Technology to an Ancient Art," Palo Alto Times, 12 Nov. 1979.
} 
Conditioning sound waves, acoustics, signal processing - intelligibility problems, and signal processing - underwater acoustics." 70 The next year, CCRMA followed up by submitting a grant request to the Office of Naval Research. Similarly, in 1986 Pierce directed CCRMA's attention to a man from the National Security Agency "who expressed considerable interest in supporting work on a vocal-tract model for high-quality speech and song. The chances of success are 40-60\%, even in these bad times." 71

In an institutional environment that struggled with tensions and contradictions between basic and applied research, military and civilian applications, and disciplinary rigor versus interdisciplinary problem solving, CCRMA managed - via innovations in both organization and its multivocal research tools - to position itself as embodying all of these things simultaneously. That flexibility allowed CCRMA to secure resources from stakeholders with very different objectives and to nimbly reposition itself as the funding environment changed. The multivocality of CCRMA's tools, practices, and personnel also allowed it to connect into very different networks both inside and outside Stanford and thereby to accrue legitimacy and ameliorate conflict.

\section{EARNING MERIT FOR CCRMA}

That is, the formation of a constituency for computer music at Stanford, and its formalization under the umbrella of CCRMA, were facilitated by the fact that computer music offered something for everyone during a time of crisis. For idealists, it offered a more humanistic, holistic vision of science and engineering; for doves, the possibility of making military-industrial technologies relevant to civilian applications; for embattled administrators, a way to use an expansive form of interdisciplinarity to lubricate campus friction; and for cash-strapped, protest-besieged scientists and engineers, a way to solicit money from both military funders and civilian agencies, private philanthropies, and commercial firms. That diversity of funding in turn allowed CCRMA's members and (especially) Stanford's administrators to demonstrate to protesters that some of their demands were being met.

For CCRMA and electronic music to help those stakeholders achieve their aims, however, news of CCRMA's work had to be distributed widely. That is, if the budgetary and legitimacy crises of the late '60s and early '70s helped open the door for music to enter the laboratory at Stanford, those crises also required that computer music come back out of the laboratory and be heard by anyone who would listen. Trustees needed to be shown that Stanford faculty members were looking for funding wherever they could find it; campus activists needed to be shown that Stanford engineers were in the process of turning toward more civilian, socially relevant projects; administrators needed to be shown that CCRMA really could bring different sides of the campus together.

This theme played out wherever Stanford engineers sought expansive interdisciplinarity, civilian applications, and diversified funding in the late '60s and early '70s. For instance, the AEL takeover of 1969 prompted Stanford's School of Engineering

\footnotetext{
${ }^{70}$ Sponsored Projects Office to Patte Wood, CCRMA, handwritten memorandum, 1985, SUA, ACCN 2001-262, box 13.

${ }_{71}$ John R. Pierce to John Chowning, Patte Wood, and Julius Smith, memorandum, 15 Dec. 1986, SUA, ACCN-2001-262, box 4.
} 
to prominently tout its faculty members' work on civilian-relevant applications such as biomedical sensors and aids for the handicapped-work that had previously been buried at the back of annual reports. ${ }^{72}$ Similarly, the commingling of music and engineering played an outsize role in Stanford's promotion of itself (often, to itself) as an institution capable of overcoming Vietnam-era adversity.

For instance, President Lyman, in bemoaning the divisions tearing the university apart, made explicit gestures to music and computing as fields whose practitioners had far more in common than they might know or admit:

It is an arrogant assumption of some humanists that no computer man reads Keats, and no electronics buff can dig Scarlatti. It is an arrogant counter-assumption of some technologists that no humanist has anything important to contribute to life in the technitronic age of the future. The university exists in part to attack such arrogant parochialisms. ${ }^{73}$

Similarly, researchers whose livelihoods were threatened by the protests against oncampus classified work eagerly embraced music as one of the civilian application areas benefiting from nominally secret research. As David Gray, a researcher in the AEL, wrote to Kenneth Arrow in 1966,

That classified research will benefit the human race is apparent when one surveys the ever more numerous outgrowths of such research. To enumerate, there are SLAC [the Stanford Linear Accelerator Center], air traffic control, jet transportation, and isotopes for cancer research. ... Musical instruments will be synthesized by a computer eventually placing an entire symphonic orchestra in the hands of a composer who will need only to communicate his composition to the synthesizer. He will then be able to listen and improve. At Stanford, research in encoding, in propagation of optical data processing, in integrated circuits, and in acoustic couplers are all relevant to such future development. ${ }^{74}$

When members of the divided university sought common ground, therefore, electronic music was one of a handful of guiding examples of how to do so.

For instance, when an ad hoc committee of faculty members was formed in 1971 to address "increased campus interest in research," it put together a research "exposition extending over the entire campus community. Interdisciplinary activities particularly are desired," 75 such as

the use of holography (three-dimensional laser holography) in displaying art objects, a continuous interactive opinion poll with a computer terminal, the use of electronic devices to help the blind and to measure medical data inside the body, and a presentation of computer-composed music. ${ }^{76}$

As a site of multivocal activity, the research that later became CCRMA's focus was an obvious fit for a public exhibition of Stanford faculty members' abilities to work

\footnotetext{
72 Stanford Electronics Laboratories, Stanford University Electronics Research Review 11 (12 Aug. 1969), SUA, Collection 3120/4 STAN.

${ }^{73}$ Quoted in "Defense Research Will Shift" (cit. n. 28).

${ }^{74}$ Gray to Kenneth Arrow, memorandum, 2 July 1966, SUA, SC 132, ACCN 97-093, William Rambo Papers, folder 7, "Stud. Unrest, 1966-1."

75 "Research Exposition Is Planned; Organizational Meeting Tomorrow," Campus Report, 9 Dec. 1970.

76 “Research Exposition Is Planned," Campus Report, 27 Jan. 1971.
} 
across disciplinary lines and to broaden the university's research portfolio beyond national security concerns.

Stanford administrators were particularly eager to have campus research reach out to the local communities of the San Francisco Peninsula, driven by pressure both from those local communities and from campus activists and reform-minded faculty who insisted that "as Stanford has grown in national prestige in the last twenty years, it has become simultaneously more and more isolated politically, educationally, and financially from its immediate community, neither serving it nor supported by it." 77 Few areas of research lent themselves better to overcoming such isolation than a performance art such as computer music. Indeed, CCRMA's leaders viewed CCRMA, and before it SAIL, as natural venues for connecting Stanford to its environs. A 1974 NSF funding application described the center's outreach efforts:

\section{Publications and Performances}

A normal function of the Center, indeed an obligation, will be the publication of results on a lay level as well as technical. Publications and tapes for performance could then be made available to large numbers of communities throughout the nation through the Executive Directors of the State Arts Councils.

\section{Site Visits and Symposia}

It is a normal circumstance to have a large number of visitors at the Stanford Artificial Intelligence Laboratory. Over the past years we have given demonstrations to groups ranging from school children to professionals in the field. With a relatively independent satellite system as proposed, we could significantly expand visits without causing inconvenience to the main laboratory. ...

As a part of the nation's Bicentennial, we propose that the Center at Stanford, an example of computer based interdisciplinary research and composition, organize a series of concerts of computer music, lecture-demonstrations, laboratory visits, and a symposium in the Spring and Summer of 1976. In this way, the public can share the excitement of applying its advanced technology to the discovery of new knowledge regarding sound and perception and to new means for the composition and performance of music. ${ }^{78}$

These efforts met with good success, too: by the early 1980s, CCRMA concerts had already attracted over a thousand attendees. ${ }^{79}$

\section{OTHER FORMS OF TRANSLATION}

Performances for local communities were by no means the only form of outreach envisioned for CCRMA. Chowning and other leaders organized their center to translate research out to society at large. Some of those conduits of translation were adapted from early Cold War centers such as the Microwave Lab; others emerged partly in response to the conditions of the early '70s.

One obvious CCRMA output was personnel. Students such as Dick Moore and Andy Moorer from CCRMA's early cohorts received offers from organizations, such

\footnotetext{
${ }^{77}$ Flyer for "open meeting sponsored by FPAG (Faculty Political Action Group)," [ca. 18 Feb. 1971], SUA, Stanford University Sponsored Projects Office SC 344, ACCN 1987-130, box 1, folder 1, "Committee on Research 1970-71."

${ }^{78}$ Chowning, Smith, and Cohen, "Computer Music Facility" (cit. n. 47), 5-6.

79 Xavier Serra and Patte Wood, eds., "Overview: Center for Computer Research in Music and Acoustics" (Stanford Department of Music Report Stan-M-44, March 1988); Julia Sommer, "Computer Music Audiences Mushroom," Stanford News Office press release, 28 June 1982.
} 
as the Eastman School and the University of California, San Diego, that were looking to set up similar efforts in computer music. Musicians such as Györgi Ligeti stayed at CCRMA as composers in residence, then left to spread the word about computer music in general and Stanford's program in particular. Thus, through the production of personnel, CCRMA was able to export its organizational model. Indeed, that seems to have been one of Chowning's ambitions from the beginning. As the 1974 NSF proposal put it, CCRMA and its multivocal tools would serve "as a prototype for other and future systems." 80 Within the first few years of CCRMA's existence, the center had influenced programs in locations as far-flung as Paris and Hamburg. ${ }^{81}$

The production of personnel to export institutional models was, in some ways, an aim borrowed from semi-independent labs of the early Cold War such as Stanford's Center for Materials Research. ${ }^{82}$ By the late '60s, however, leaders of Stanford's semi-independent research centers saw a need to produce something more than personnel. One path Stanford researchers increasingly took was to patent their research and seek firms to license those patents; some even founded start-ups to commercialize their research themselves. Music technologies played an outsize, if underappreciated, role in the exploratory commercialization of Stanford research in the '70s. For instance, one of Stanford's most active patenters in this era was Calvin Quate in applied physics and EE; among Quate's many patent disclosures was one from 1974 for an "electronic device for converting written music to audible sound." ${ }^{33}$ CCRMA personnel, too, eagerly looked for commercial spin-offs from their research. Chowning, as noted, was an early and frequent patenter, and some of his intellectual property eventually became the most lucrative portion of Stanford's portfolio.

Commercial translations were not confined to patents and licenses, however. CCRMA also used its multivocal technology as a basis for cooperative research with industry, which the firms hoped might stimulate new uses (and hence markets) for their products. For example, the center submitted a 1979 grant application titled "Intelligent Systems for Music Analysis" under the NSF's university-industry cooperative research program, proposing to join with the Palo Alto-based machine-control firm Systems Control. Though Systems Control had no interest in music per se, it had much to gain from other applications of the work that happened to employ music as a context. Similarly, in 1975 James Angell (an EE faculty member) used money from Stanford's new Research Development Fund, "established to stimulate innovative research endeavors by both junior faculty and faculty who were redirecting their research interests" (i.e., faculty interested in adopting the relevant-research agenda), to support Moore's graduate work and to collaborate with Ed Taylor, an engineer at EPA Electronics. Moore, Taylor, and Angell then approached Intel, which told them "they would be happy to provide us with any amount of the componentry (especially integrated circuits) which they make that might be of use to us," presumably in hopes of finding new applications for their products. ${ }^{84}$

\footnotetext{
${ }^{80}$ Chowning, Smith, and Cohen, "Computer Music Facility" (cit. n. 47), 4.

${ }^{81}$ John Chowning, John Grey, James Moorer, Loren Rush, and Leland Smith, "Center for Computer Research in Music and Acoustics: Overview," 1 Dec. 1977.

${ }^{82}$ David Kaiser, "Cold War Requisitions, Scientific Manpower, and the Production of American Physicists after World War II," Historical Studies in the Physical Sciences 33 (2002): 131-59.

${ }^{83}$ Docket number S74-09, SUA, CCRMA ACCN 2001-262, box 7.

${ }^{84}$ Angell to Pat Devaney, "Re: RDF Report," 14 Jan. 1976, SUA, Richard Lyman Papers, SC 215 Series 3, box 23, folder "National Science Foundation, 3/1976-3/1977."
} 
The most far-reaching of CCRMA's translations - at least in terms of physical distance-emerged from its collaborations with NASA. For its part, as early as 1962, NASA announced that it was "particularly desirous that the environment in which space research is conducted will be characterized by a multidisciplinary effort which draws upon creative minds from various branches of the sciences, technology, commerce and the arts." 85 Indeed, a 1972 NASA-Stanford agreement elicited proposals from "Art History, Genetics, Psychiatry, the Graduate School of Business, and Geology." ${ }^{86}$ In that light, it is worth noting that there was an active Mars research group at the Stanford Artificial Intelligence Project, where CCRMA was based for its first years. In fact, Mike McNabb, one of CCRMA's earliest PhD students, composed a suite, Music for Mars in 3-D, tied to stereographic images from NASA's Mars Viking spacecraft. Another of McNabb's creations, Invisible Cities, was a ballet featuring an automated robot as a dancer and a computer-music soundtrack as the orchestra. McNabb's collaborators on the ballet included both the ODC/San Francisco Dance Company and the Veterans Administration Robotic Aid project, the latter of which was experimenting with how to employ robotics to assist injured Vietnam veterans.

\section{CONCLUSION}

As the other articles in this volume illustrate, music and science have a long common history. In this article, we have focused upon the organizational and institutional aspects of this relationship in a twentieth-century research university. Specifically, we have elaborated upon the ways in which Vietnam War-era debates at Stanford (and elsewhere) forged a new institutional environment that emphasized radical interdisciplinarity and relevant research. Although the activists and interests engaged in these discussions maintained significant heterogeneity, an emergent research center that was explicitly focused upon the intersection of music and science found both legitimacy and resources in this new environment. In turn, the work conducted at this center, in terms of both musical composition and technical advance, has had farreaching impact in a variety of spheres.

Our analysis has focused particular attention on computer-music research methods and tools as multivocal technologies that span both disciplinary boundaries and areas of applied interest. In this way, the technologies themselves both reflected and facilitated the emergent institutional environment at Stanford. Even as Vietnam-era debates waned and campus interests turned firmly toward Silicon Valley entrepreneurship by the close of the century, the generality and flexibility of computer music allowed CCRMA members to orient toward start-up companies and new models of university intellectual property. Similarly, as the stigma attached to funding and projects associated with the military-industrial complex waned from the late '70s on-

85 "Memorandum of Understanding between National Aeronautics and Space Administration and Leland Stanford Junior University Concerning Research Facilities Grant NsG(f) 2-62," 15 Dec. 1966, SUA, Richard Lyman Papers, SC 215 Series 1, box 125, folder "National Aeronautics and Space Administration."

${ }^{86}$ Jon Erickson, sponsored projects officer, to Harold Einhorn, associate vice president for academic programs, California State University, San Francisco, 22 July 1974, SUA, Richard Lyman Papers, SC 215 Series 1, box 125, folder "National Aeronautics and Space Administration." 
ward, CCRMA employed its multivocal research tools to seek funding from the NSA and the Office of Naval Research.

Ultimately, our article sheds light upon the ways in which organizational and institutional arrangements can give rise to and underpin the environments in which music and science interact. From this perspective, Chowning's 1975 description of CCRMA's role- "to provide intellectual ventilation as well as coordination" 87 might be equally apt to describe the role of institutional environments in structuring the relationship between music and science as a whole.

${ }^{87}$ Hertelendy, “Stanford's Musical 'Marriage’” (cit. n. 50). 